\section{Horticultural Research Crucial for Plant Conservation and Ecosystem Restoration}

\author{
Thomas E. Marler ${ }^{1}$ \\ Western Pacific Tropical Research Center, College of Natural and Applied \\ Sciences, University of Guam, UOG Station, Mangilao, GU 96923
}

The sixth mass extinction event is unfolding (Ceballos et al., 2017). Unlike the historical mass events (Raup and Sepkoski, 1982), the contemporary phenomenon is anthropogenic. This biodiversity crisis is one of the defining components of the Anthropocene (Crutzen, 2006; Davies, 2016) that contemporary authors of HortScience articles live and work within.

Over the past few years, these issues have ushered in an increasing number of HortScience manuscript submissions that address conservation of threatened plant species and restoration of degraded habitats. The submissions have been published primarily in the "Propagation and Tissue Culture" or "Breeding, Cultivars, Rootstocks, and Germplasm Resources" categories, whereas many have appeared in the "Miscellaneous" category because of features of the submissions that do not conform to any of the established sections. The addition of a dedicated "Conservation and Restoration" HortScience category was recently proposed and approved as a means of valorizing the importance of horticultural research to conserving threatened plant species and restoring degraded habitats.

As the biodiversity crisis associated with the sixth mass extinction increases in severity, members of all branches of science have been challenged to do something about it (Lovejoy, 2017). Ambitious conservation and restoration goals demonstrate the global priority for addressing biodiversity conservation, and many regional, national, and international initiatives are being conceived and implemented worldwide. The approaches in the calls for action have migrated toward large-scale partnerships that include agencies, organizations, land owners, scientists, and stakeholders of all kinds (Jacobs, 2017; Reed et al., 2016; Schmeller et al., 2017; Suding et al., 2015).

This new dedicated category in HortScience may be used by horticultural researchers to exemplify horticultural examples of these new inclusive global approaches that provide insights to all stakeholders. The eventual accumulation of reports in this category may showcase that financing horticultural research within these global initiatives is

Received for publication 21 Aug. 2017. Accepted for publication 10 Oct. 2017.

${ }^{1}$ Corresponding author. E-mail: thomas.marler@ gmail.com. a respectable investment with great returns. The fields of conservation and restoration horticulture are intrinsically multidisciplinary. Ideally, knowledge transfer would flow in both directions. Policy makers and funding agencies would acknowledge the value of horticultural techniques that can contribute to the success of their specific projects. In addition, horticulturists would collaborate with the conservation and restoration community to identify pertinent applications for their contributions.

My interest in how horticultural research can contribute to conservation of threatened species evolved because of relatively recent personal experiences with two endangered tree species on the island of Guam, Cycas micronesica K.D. Hill and Serianthes nelsonii Merr. The initiation of my involvement in S. nelsonii conservation was especially influential in developing my overview of the role of horticultural research within recovery attempts of threatened plant species. The 1994 recovery plan for this tree (USFWS, 1994) called for research to inform adaptive management decisions and the production of thousands of plants for use in species recovery projects. When I acquired a 2012 contract to study the limitations to recruitment in natural habitat and nursery production of transplants, almost two decades of the funded projects had generated no new published empirical research. Thereafter, the 2016 assessment of the species recovery progress contained 20 years of gray matter references such as personal communications, memorandums, trip reports, project progress reports, and emails (USFWS, 2016). Relying on anecdotes in this manner puts at risk the success of conservation programs (Sutherland et al., 2004). But the final 2 years of the 1994-2016 overview of progress on species recovery contained contemporary refereed publications that resulted from the decision to bring a research horticulturist into the conservation agenda.

The protocols available to conduct practical research to answer questions concerning endangered plants are severely restricted by the total population size of plants available for collection of propagules and the mandate that all experimental procedures remain nondestructive to the eventual transplants. The protocols available to address research needs of nascent restoration projects are hindered by the learning-as-you-go features of designing experiments. Most disciplines of plant science do not include the academic and practical experiences that match horticulture for addressing these types of research confines. As a result, horticulturists may be uniquely positioned to address this style of research because of the content and diverse nature of the various horticulture subdisciplines.

\section{Submissions}

Authors now have the option of submitting appropriate manuscripts to the "Conservation and Restoration" category in HortScience. The manuscripts for this category need to clearly address plant conservation or restoration issues that are global or regional in relevance but remain horticultural in context and mechanics. HortScience is not a general biology or ecology journal. Manuscripts that focus on the ecological context of conservation or restoration science belong in one of the numerous ecology and conservation journals.

The merits of horticulture research to this new HortScience category may be exemplified by mentioning several examples. Floriculture research must acknowledge the need to maximize visual and olfactory quality of a single flower stem, sustain that quality between harvest and retail purchase, then sustain that quality even more after the retail purchase. Treatments employed to produce products for high-volume consumer dates cannot be inaccurate, as missing the desired shipping dates by 1 or $2 \mathrm{~d}$ may spell disaster for the horticulture operation. Fruit science research must acknowledge the need to maximize sensory quality at harvest and sustain that quality through the supply chain until the ultimate retail sale. Horticultural researchers are required to approach trenchant research questions and communicate the new knowledge.

The desired prerequisite for submission of a conservation manuscript to this category is that the model species is formally listed under any regional, national, or international listing of threatened species. For example, S. nelsonii was placed on the Guam Endangered Species List in 1981, was listed under the United States Endangered Species Act as Endangered in 1987, was placed on the Commonwealth of the Northern Mariana Islands Endangered Species List in 1991, and was updated as Critically Endangered on the Red List of the International Union for Conservation of Nature and Natural Resources in 1998 (USFWS, 1987, 2012; Wiles, 1998). Any one of the four formal listings could be used to justify submission of a $S$. nelsonii horticulture manuscript to this HortScience category.

Restoration of degraded habitats has become an important part of the response to the global biodiversity crisis (Brancalion and Chazdon, 2017; Jordan et al., 1988; Menz et al., 2013; Miller et al., 2017), and becoming involved in restoration programs allows horticulturists to make a contribution to the global biodiversity crisis. Restoration horticulture manuscripts that formally contribute to established restoration programs are desired. Inclusion of a citation that describes the 
project, initiative, coalition of restoration stakeholders, or use of the species in past restoration projects (Baldos et al., 2015) would improve the quality of the submissions.

As horticulturists continue to accumulate more data showcasing the role of horticulture in conservation and restoration, our understanding and capacity to stop and reverse this global biodiversity crisis can only improve. Think globally so that your horticultural research fits into an international agenda, research locally so that your particular set of horticultural skills best facilitate the regionally appropriate research, and publish in HortScience.

\section{Literature Cited}

Baldos, O.C., J. DeFrank, and G.S. Sakamoto. 2015. Germination responses of dormant tanglehead (Heteropogon contortus) seeds to smoke-associated stimulatory compounds, karrikinolide and cyanide. HortScience 50:421429.

Brancalion, P.H.S. and R.L. Chazdon. 2017. Beyond hectares: Four principles to guide reforestation in the context of tropical forest and landscape restoration. Restor. Ecol. 25:491-496.

Ceballos, G., P.R. Ehrlich, and P. Dirzo. 2017. Biological annihilation via the ongoing sixth mass extinction signaled by vertebrate population losses and declines. Proc. Natl. Acad. Sci. USA 114:E6089-E6096.

Crutzen, P.J. 2006. The "Anthropocene", p. 1318. In: E. Ehlers and T. Krafft (eds.). Earth system science in the anthropocene. Springer, Berlin, Germany.

Davies, J. 2016. The birth of the anthropocene. Univ. California Press, Oakland, CA.

Jacobs, K.R. 2017. Teams at their core: Implementing an "all LANDS approach to conservation" requires focusing on relationships, teamwork process, and communications. Forests 8:246.

Jordan, W., R. Peters, and E. Allen. 1988. Ecological restoration as a strategy for conserving biological diversity. Environ. Mgt. 12:55-72.

Lovejoy, T.E. 2017. Extinction tsunami can be avoided. Proc. Natl. Acad. Sci. USA 114:8440-8441.

Menz, M.H.M., K.W. Dixon, and R.J. Hobbs. 2013. Hurdles and opportunities for landscape-scale restoration. Science 339:526-527.

Miller, B.P., E.A. Sinclair, M.H.M. Menz, C.P Elliott, E. Bunn, L.E. Commander, E. Dalziell, E. David, B. Davis, T.E. Erickson, P.J. Golos, S.L. Krauss, W. Lewandrowski, C.E. Mayence, L. Merino-Martín, D.J. Merritt, P.G. Nevill, R.D. Phillips, A.L. Ritchie, S. Ruoss, and J.C. Stevens. 2017. A framework for the practical science necessary to restore sustainable, resilient, and biodiverse ecosystems. Restor. Ecol. 25:605-617.

Raup, D.M. and J.J. Sepkoski, Jr. 1982. Mass extinctions in the marine fossil record. Science 215:1501-1503.

Reed, J., J. Van Vianen, E.L. Deakin, J. Barlow, and T. Sunderland. 2016. Integrated landscape approaches to managing social and environmental issues in the tropics: Learning from the past to guide the future. Glob. Change Biol. 22:2540-2550.

Schmeller, D.S., J. Niemelä, and P. Bridgewater. 2017. The Intergovernmental Science-Policy
Platform on Biodiversity and Ecosystem Services (IPBES): Getting involved. Biodivers. Conserv. 26:2271-2275.

Suding, K., E. Higgs, M. Palmer, J.B. Callicott, C.B. Anderson, M. Baker, J.J. Gutrich, K.L. Hondula, M.C. LaFevor, B.M.H. Larson, A. Randall, J.B. Ruhl, and K.Z.S. Schwartz. 2015. Committing to ecological restoration. Science 348:638-640.

Sutherland, W.J., A.S. Pullin, P.M. Dolman, and T.M. Knight. 2004. The need for evidencebased conservation. Trends Ecol. Evol. 19:305-308.

USFWS (U.S. Fish and Wildlife Service). 1987. Endangered and threatened wildlife and plants; determination of endangered status for Serianthes nelsonii Merr. (Hayun Lagu or Tronkon Guafi). Federal Register 52(32:4907-4910.

USFWS (U.S. Fish and Wildlife Service). 1994. Recovery plan for Serianthes nelsonii. U.S. Fish and Wildlife Service, Region 1, Portland, OR. 9 Oct. 2017. <http://www.fws.gov/pacificislands/ recoveryplans.html $>$.

USFWS (U.S. Fish and Wildlife Service). 2012. Pacific Islands Fish and Wildlife Office, endangered species in the Pacific Islands, recovery plan for the Serianthes nelsonii. 9 Oct. 2017. <http://www.fws.gov/pacificislands/flora/ serianthes_nelsonii.html>.

USFWS (U.S. Fish and Wildlife Service). 2016. 5-year review: Serianthes nelsonii. 9 Oct. $2017<\mathrm{https}: / /$ ecos.fws.gov/docs/five_year_review/ doc5127.pdf $>$.

Wiles, G. 1998. Serianthes nelsonii. The IUCN Red List of Threatened Species 1998: E.T30437A9550169. 9 Oct. 2017. <http://dx.doi.org/10.2305/IUCN. UK.1998.RLTS.T30437A9550169.en>. 